\title{
Compartilhando sonhos: \\ Bem-Viver, Pedagogia Freinet, Arte/Educação e Educação das Relações Étnico-Raciais
}

\author{
Sharing dreams: Good Living, Freinet Pedagogy, Art/Education and Education of Ethnic-Racial Relations \\ Compartiendo sueños: Buen Vivir, Pedagogía Freinet, Arte/Educación y Educación de las Relaciones Étnico- \\ Raciales
}

\author{
Alessandra Guerra da Silva Oliveira ${ }^{1}$; Carolina laureto Hora ${ }^{2}$; \\ GABRIELA LUCHESI MARTINS ${ }^{3}$ \\ Universidade Federal de São Carlos, UFSCAR, SÃo CARLos-SP, BraSIL
}

\begin{abstract}
RESUMO
Diante do momento de crise sanitária, ambiental, ética e econômica mundial, ocasionadas pela pandemia do Coronavírus, o presente estudo se propõe a esperançar mudanças no viver em sociedade a partir dos pensadores indígenas. O objetivo deste ensaio é dialogar com reflexões críticas acerca do pensamento colonial, das acomodações e desesperanças de nosso tempo, do contexto social, político, econômico em que estamos vivendo e trazer considerações sobre o conceito de Bem-Viver como possibilidade de mudanças. Ao buscar uma interface com os temas que permeiam as pesquisas das autoras/pesquisadoras deste estudo, pretende-se estabelecer diálogos entre o Bem-Viver e a Pedagogia Freinet, a Arte/Educação e a Educação das Relações Étnico-Raciais enquanto possibilidades de atuação no campo da educação alinhadas com a cosmovisão indígena.

Palavras-chave: Bem-Viver. Pedagogia Freinet. Arte/Educação. Educação das Relações Étnico-Raciais.
\end{abstract}

\begin{abstract}
In the face of a global health, environmental, ethical and economic crisis caused by the Coronavirus pandemic, the present study proposes to hope for changes in living society from indigenous thinkers. The purpose of this essay is to dialogue with critical reflections about colonial thought, the accommodations and hopelessness of our time, the social, political, economic context in which we are living and bring considerations about the concept of Good Living as a possibility for changes. In seeking an interface with the themes that permeate the researches of authors / researchers of this study, it's intended to establish dialogues between Good Living and Freinet Pedagogy, Art / Education and the Educacion of Ethnic-Racial Relations as possibilities of action in the field of education aligned with the indigenous worldview.
\end{abstract}

Keywords: Good Living. Freinet Pedagogy. Art Education. Education of Ethnic-Racial Relations.

\section{RESUMEN}

Frente a una crisis sanitaria, ambiental, ética y económica mundial causada por la pandemia del coronavirus, este estudio se propone a esperar cambios en la vida en la sociedad desde los pensadores indígenas. El propósito de este ensayo es dialogar con reflexiones críticas sobre el pensamiento colonial, las acomodaciones y desesperanza de nuestro tiempo, el contexto social, político, económico en el que vivimos y plantear reflexiones sobre el concepto de Buen Vivir como posibilidad de cambios. Al buscar una interfaz con los temas que permean las investigaciones de las autoras/investigadoras de este estudio, se pretende establecer diálogos entre Buen Vivir y Pedagogía Freinet, Arte/Educación y Educación de las Relaciones Étnico-Raciales como posibilidades de acción en el campo de la educación alineado con la cosmovisión indígena.

Palabras clave: Buen Vivir. Pedagogía Freinet. Arte Educación. Educación de las Relaciones Étnico-Raciales.

\footnotetext{
1 Doutoranda em Educação pelo Programa de Pós-Graduação em Educação da UFSCar. E-mail: aleguerraoliveira@gmail.com. ORCID: https://orcid.org/0000-0002-2304-4052.

Doutoranda em Educação pelo Programa de Pós-Graduação em Educação da UFSCar. E-mail: carollaureto@gmail.com. ORCID: https://orcid.org/0000-0001-9308-989X.

3 Mestranda em Educação pelo Programa de Pós-Graduação em Educação da UFSCar. E-mail: gluchesimartins@gmail.com. ORCID: https://orcid.org/0000-0001-6835-177X.
} 


\section{INTRODUÇÃOO}

Este estudo foi escrito em um contexto social, econômico e histórico de grandes mudanças e perturbações mundiais: crise da COVID-19, crise sanitária, econômica, ética e ambiental. No Brasil, a crise provocada pelo Coronavírus desmascarou e acentuou a crise social, política, econômica em que já estávamos inseridos, vivenciada há mais de quarenta anos (SANTOS, 2020). Enfrentamos o desrespeito e descaso com os seres humanos e a natureza, os desmatamentos exagerados e desenfreados da vegetação - principalmente da floresta amazônica, devastação dos recursos naturais e minerais, aumento das desigualdades sociais e raciais e maior marginalização das pessoas e tentativas do governo de enfraquecer os movimentos e grupos sociais.

Neste momento histórico de crises ambientais, desgoverno político e pandemia mundial que trouxe perda de esperanças e frustrações realizamos reflexões sobre o tema do Bem-Viver e dialogamos com autores como: Acosta (2016), Krenak (2020), Brandão (2005), Santos (2007; 2020), Quijano (2013) e Kopenawa e Albert (2015) na disciplina "Ócio, Bem-Viver e Educação" ministrada pelo Prof. Dr. Luiz Gonçalves Junior no Programa de Pós-Graduação em Educação (PPGE) da Universidade Federal de São Carlos (UFSCar).

Entrar em contato com as reflexões desses autores que nos apresentam possibilidades de um novo modelo de sociedade - tendo em vista que Bem-Viver para cada um deles tem uma conotação específica, porém todos se alinham na significação do conceito como uma concepção de vida em sociedade a partir da coletividade, da cooperação, da sustentabilidade e da integração entre todos os seres da natureza, da qual a humanidade faz parte, em detrimento dos valores correntes do individualismo, da competição, do consumismo e superioridade humana perante os demais seres - foi reconfortante e nos ajudou a superar o desalento e esperançar transformações sociais. É este esperançar que move o presente ensaio.

Nas palavras de Freire (1992), esperançar remete à movimentação e não à espera e Cortella (2015) ao buscar compreensões dos dizeres freirianos, discorre que:

\footnotetext{
É preciso ter esperança, mas ter esperança do verbo esperançar; porque tem gente que tem esperança do verbo esperar. E esperança do verbo esperar não é esperança, é espera. Esperançar é se levantar, esperançar é ir atrás, esperançar é construir, esperançar é não desistir! Esperançar é levar adiante, esperançar é juntar-se com outros para fazer de outro modo (CORTELLA, 2015, p. 22).
}

Freire (1992) aborda a esperança como necessidade ontológica e discorre que a esperança precisa da prática para tornar-se concretude histórica. Segundo o autor temos que alimentar sempre a esperança, mesmo vivenciando os problemas políticos, econômicos e sociais, não podemos nos acomodar, usar a desesperança como pretexto para desistir de lutar. As mudanças são possíveis, mas para que elas ocorram, é necessário ter fé e esperança com consciência e ação crítica, acreditar em possibilidades de mudanças e transformações e buscá-las lutando.

O objetivo deste ensaio é dialogar com reflexões críticas acerca do pensamento colonial, das acomodações e desesperanças de nosso tempo, do contexto social, político, econômico em que estamos vivendo e trazer considerações sobre o conceito de BemViver como possibilidade de mudanças, fazendo interface com os temas que permeiam as pesquisas das autoras/pesquisadoras deste estudo, ou seja, relacionando o Bem-Viver com a Pedagogia Freinet, Arte/Educação e Educação das Relações Étnico-Raciais. 


\section{CONSIDERAÇÕES SOBRE O CONTEXTO ATUAL: O "MAL-VIVER"}

Em nosso contexto atual, marcado por uma polarização política e ideológica, compreendemos o Mal-Viver como a vida em desarmonia, na qual há um desequilíbrio entre o ser humano e as demais formas de vida, entre os ciclos da natureza e o atual modelo econômico-social que direciona a configuração da sociedade e cultura humanas.

Santos (2007) diz que "[...] o pensamento moderno ocidental é um pensamento abissal", que "[...] consiste num sistema de distinções visíveis e invisíveis" (SANTOS, 2007, p. 71). Tais distinções foram estabelecidas no momento em que foram feitas divisões cartográficas entre o Velho e o Novo Mundo na era colonial, que permanecem ainda hoje, tendo em vista que essas linhas radicais dividem a realidade social em dois lados distintos: "este" lado da linha, e o "outro" lado da linha.

Santos (2007) diz que o outro lado da linha, o Sul geográfico e metafórico, composto por países subdesenvolvidos, sofreu um grande apagamento, e que sua invisibilidade é o que alimenta a existência do lado da linha composto pelos países do norte. Para Santos (2007), essa forma de operacionalização da sociedade é uma realidade ainda hoje, pois o pensamento moderno ocidental ainda opera mediante linhas abissais que separam o mundo humano do mundo subumano, em nome de princípios e práticas hegemônicas, tal como ocorria na era colonial.

Assim, Santos (2007) explicita que, no campo do conhecimento, estabelecem-se os critérios de verdadeiro e falso, de verdades científicas e não-científicas para visibilizar, de um lado da linha, os conhecimentos relevantes e comensuráveis da ciência, bem como os conhecimentos incomensuráveis dos ramos da filosofia e da teologia, por exemplo, enquanto do outro lado da linha, encontram-se invisíveis os conhecimentos populares, leigos, indígenas, que estão para além do universo do verdadeiro e do falso.

A premissa da diversidade está no cerne da teoria desenvolvida por Santos (2007), que concebe um pensamento pós abissal como um saber ecológico, uma ecologia dos saberes, basicamente uma contra-epistemologia, que reconhece a existência de uma pluralidade de formas de conhecimento além do conhecimento científico. Esse novo saber, seria pautado na experiência social do Sul global, ou seja, do outro lado da linha, prevê "[...] um aprender com o Sul usando uma epistemologia do Sul" (SANTOS, 2007, p. 85). A ecologia dos saberes confronta a monocultura da ciência moderna, no entanto, o autor acredita na co-presença dessas duas perspectivas epistemológicas, pois acredita que "[...] o reconhecimento da persistência do pensamento abissal é condição sine qua non para começar a pensar e a agir para além dele" (SANTOS, 2007, p. 85).

Krenak (2020) também nos ajuda a refletir sobre nosso contexto atual, questiona se realmente somos uma humanidade que se importa com a vida. Segundo o autor, o confinamento, isolamento involuntário, já ocorre há algum tempo nas comunidades indígenas, antes mesmo da pandemia, algo que só trouxe fortalecimento e resiliência para os povos indígenas. Krenak (2020) faz críticas ao nosso governo e ao modelo de vida artificial que a humanidade adotou, modelo capitalista que consome e destrói sem se preocupar com as consequências.

Segundo Krenak (2020) a natureza nos quer ensinar algumas coisas com a COVID-19, a pandemia trouxe mudanças na forma de nos relacionarmos, o isolamento social possibilitou reflexões sobre o modelo de vida que adotamos como única existente, ponderações sobre o rompimento com o sistema capitalista que nos foi imposto, para pararmos de pensar individualmente e vivermos pensando no coletivo,

\footnotetext{
${ }^{4}$ Tenha-se em vista que "este" lado da linha referido pelo autor, diz respeito ao mundo ocidental, mais especificamente à Europa onde o autor inclusive se localiza geograficamente, pois reside em Portugal.
} 
assim como a cultura indígena vem nos ensinando. No encontro de Krenak com Sidarta Ribeiro no evento \#NaJanelaFestival organizado pela Companhia das Letras ${ }^{5}$, o tema discutido é justamente a urgência de a coletividade indígena aconselhar a humanidade não indígena, individualista, uma luta que visa ajudar na construção de um modo de vida social mais coletivo e responsável, pois de acordo com Krenak, o planeta está nos mostrando que nós humanos somos indigestos, e precisamos nos conectar com o organismo vivo que é a Terra e toda a infinidade de espécies que a habitam, em comunhão. Assim, nos mostra o quão relevante é nossa presença enquanto seres em um mundo maior do que as relações humanas:

\begin{abstract}
A minha sugestão é muito difícil de colocar em prática. Pois teríamos de parar todas as atividades humanas que incidem sobre o corpo do rio, a cem quilômetros nas margens direita e esquerda, até que ele voltasse a ter vida". Então um deles me disse: "Mas isso é impossível". "O mundo não pode parar". E o mundo parou (KRENAK, 2020, p. 5).
\end{abstract}

Tudo parou, tudo mudou num piscar de olhos, a vida não é a mesma. Novas formas de viver tiveram que ser criadas para podermos sobreviver ao Coronavírus, tão pequeno que não conseguimos enxergar a olho nu. Krenak (2020) coloca ainda que o vírus só está matando seres humanos, e não animais e vegetais, assim a mudança e a transformação cabe a nós. Nesse sentido, o Mal-Viver, caracterizado por nosso modo errado de viver a vida, é o que está matando o mundo.

Guajajara (2020), em entrevista dada ao site Catraca Livre ${ }^{6}$, também discorre sobre a COVID-19 e pontua sua preocupação com o contágio e morte dos indígenas, principalmente dos idosos e anciãos:

[...] os nossos anciãos são a nossa biblioteca, a nossa fonte de sabedoria, os nossos tesouros vivos, que têm consigo todo um conhecimento ancestral e todo esse legado da nossa história. Quando esses anciãos morrem, levam todo esse conhecimento, que é a garantia da continuidade da nossa identidade. É o que garante a nossa cultura, nosso modo de vida e também, consequentemente, o meio ambiente (GUAJAJARA, 2020).

A líder indígena denuncia o descaso e a negligência do Governo Federal, por meio da Secretaria Especial de Saúde Indígena (SESAI), que está permitindo que a mortalidade entre os indígenas aumente de forma muito acelerada, e cobra medidas estratégicas de barreiras sanitárias e preventivas para salvar as comunidades e vidas indígenas.

\title{
REFLEXÕES SOBRE O BEM-VIVER
}

Acosta (2016) coloca que o Bem-Viver, Buen Vivir ou Vivir Bien se apresenta como uma oportunidade-possibilidade de construção coletiva de uma nova forma de

\footnotetext{
${ }^{5}$ Transmissão ao vivo realizada em 24/05/2020 que contou com a presença de: Ailton Krenak (líder indígena e ambientalista); Sidarta Ribeiro (neurocientista); Carol Pires (jornalista e roteirista. Mediadora da Mesa Redonda Virtual organizada pela Companhia das Letras no \#NaJanelaFestival). Disponível em: https://www.youtube.com/watch?v=95tOtpk4Bnw. Acesso em: 04 out. 2020.

${ }^{6}$ No Dia Mundial do Meio Ambiente, o Catraca Livre e a Change.org conversaram com a líder indígena para entender os impactos do governo Bolsonaro aos povos - 05 jun. 2020. Disponível em: https://catracalivre.com.br/cidadania/sonia-guajajara-nao-e-uma-luta-de-indio-maspelo-planeta/. Acesso em: 25 ago. 2020.
} 
vida. Turino (2016) discorre no prefácio do livro de Acosta (2016) sobre o conceito de Bem-Viver. Segundo o autor:

O Bem-Viver é uma filosofia em construção, e universal, que parte da cosmologia e do modo de vida ameríndio, mas que está presente nas mais diversas culturas. Está entre nós, no Brasil, com o teko porã dos guaranis. Também está na ética e na filosofia africana do ubuntu - "eu sou porque nós somos". Está no ecossocialismo, em sua busca por ressignificar o socialismo centralista e produtivista do século 20. Está no fazer solidário do povo, nos mutirões em vilas, favelas ou comunidades rurais e na minga ou mika andina. Está presente na roda de samba, na roda de capoeira, no jongo, nas cirandas e no candomblé. Está na Carta Encíclica Laudato Si' do Santo Padre Francisco sobre o Cuidado da Casa Comum. Seu significado é viver em aprendizado e convivência com a natureza, fazendo-nos reconhecer que somos "parte" dela e que não podemos continuar vivendo "à parte" dos demais seres do planeta (TURINO, 2016, p. 14).

Com Acosta (2016), vemos que o Bem-Viver é uma oportunidade de construção de um novo modelo de mundo, uma proposta de superação do tradicional conceito de desenvolvimento, que sugere a introdução de uma visão muito mais diversificada, onde discurso e práticas precisam dialogar, ser coerentes, modelo que deverá ser pensado e construído democraticamente e comunitariamente, conversando com os Direitos Humanos e os Direitos da Natureza.

Segundo o autor:

O mundo precisa de mudanças profundas, radicais. Urge superar as visões simplistas que transformaram o economicismo em eixo da sociedade. Necessitamos outras formas de organização social e novas práticas políticas. Para obtê-las, é imprescindível despertar a criatividade e consolidar o compromisso com a vida, para não nos convertermos em meros aplicadores de procedimentos e receitas caducas (ACOSTA, 2016, p. 20).

Para que o Bem-Viver se torne realidade em nossa sociedade, temos que recuperar a cosmovisão dos povos e nacionalidades indígenas, quebrar paradigmas, deixando as referências eurocêntricas impostas historicamente, buscando assim referências em nossas ancestralidades. Isso implica '[...] 'cidadanizar' individual e coletivamente o Estado, criando espaços comunitários como formas ativas de organização social" (ACOSTA, 2016, p. 26).

Kopenawa e Albert (2015) em sua obra A queda do céu: Palavras de um xamã yanomami, discorrem sobre as desigualdades culturais e o silenciamento das questões indígenas, tais como: genocídio, doenças que os brancos levam para as comunidades indígenas, o desmatamento das florestas e rios, tomadas das terras. Trazem discussões sobre como tratamos com desrespeito e descaso nossa história, nosso planeta e nossos ancestrais, onde destruímos e matamos os rios, as florestas pensando no desenvolvimento e em acumular mercadorias.

Assim, como enunciado no prefácio por Castro (2015), os indígenas defendem uma "[...] teoria global do lugar" (CASTRO, 2015, p. 16), na qual se compreende o mundo como casa, como floresta fecunda, ou seja, na visão de Kopenawa e Albert (2015) o lugar floresta é o centro da ecologia, e a Terra é um ser que tem coração e respira, e não uma esfera abstrata dividida em pedaços territoriais por acordos humanos gananciosos.

No livro, os autores questionam inclusive o conceito de nação, de um Brasil que se identifica como o país do futebol, do carnaval, enquanto as políticas públicas 
voltadas para a demarcação das terras indígenas retrocedem cada dia mais, e as grilagens e queimadas criminosas avançam, como tem sido noticiado e denunciado, de maneira calamitosa no período da pandemia. Nesse sentido, Castro (2015) assinala no prefácio da obra: "O Estado Nacional? Muito bem, muito bom; mas muito antes dele, há os espíritos invisíveis da floresta, as fundações metálicas da terra, a fumaça diabólica das epidemias e a doença degenerativa do céu - e nada disso tem fronteira, porteira ou bandeira" (CASTRO, 2015, p. 18).

Quijano (2013) também traz contribuições sobre o Bem-Viver, o apresenta como uma proposta de realização histórica efetiva, um modo de existência social alternativo à Colonialidade Global do Poder e à Colonialidade/Modernidade/Eurocentrada, uma descolonização do poder hegemônico imposto há mais de 500 anos.

Segundo Quijano (2013), o conceito de colonialidade é usado para acreditarmos na imparcialidade de crenças, não considerar os modos de pensar e produzir que não sejam europeus, de não pensarmos na reprodução da relação colonial e imperial. Ocorre assim um esquecimento da colonialidade e só a descolonização do ser e do saber levará a uma mudança. Descolonizar seria uma quebra de paradigmas, um rompimento com as ideias e valores que nos foram impostos pela colonização e ideais de modernidade/ desenvolvimento, conscientização das relações de dominação (financeira, ética, política, do imaginário, mentes, modos de ser, agir e viver) e opressão que vivenciamos para assim lutarmos e implementarmos ações por mudanças e transformações.

Segundo Quijano (2013) estamos caminhando na emergência de uma identidade histórica nova, já estamos imersos em um processo de reconfiguração da "Colonialidade" Global de Poder, em que existe a aceleração e o aprofundamento de uma tendência de reconcentração do controle do poder em todos os setores. O autor complementa que nessa perspectiva, a proposta de Bem-Viver é, necessariamente, uma questão histórica aberta, em defesa da vida de todos os seres do planeta, que requer ser continuamente indagada, debatida e praticada.

Tanto Santos (2007), como Quijano (2013), Kopenawa e Albert (2015), Acosta (2016), Krenak (2020) e Guajajara (2020) nos fazem refletir de forma crítica sobre o modelo capitalista vigente, nossa realidade e seus problemas sociais. Os autores trazem contribuições e propõem possibilidades de mudanças, sendo que todas elas voltam nossos olhares para a cultura das comunidades indígenas, na qual o consumismo, a depredação e distanciamento da natureza não são aceitáveis. Assim, apresentam alternativas possíveis e necessárias, a partir de sua própria experiência.

Ao longo do texto, apresentaremos possibilidades de diálogos com as alternativas propostas por esses autores, na medida em que partimos de temáticas pesquisadas e articuladas no campo da educação que se aproximam dos ideais de Bem-Viver na concepção das autoras, como prática escolar, arte e educação das relações étnico-raciais.

\section{INTERFACE do BEM-VIVER COM A PEDAgogia Freinet}

O Bem-Viver prevê que tenhamos uma sociedade mais justa, pessoas mais solidárias, qualidade de vida, vida com qualidade, conexão com o meio ambiente e uma educação que traga a transformação social na formação de indivíduos. Portanto, vamos refletir sobre o papel da educação escolar na formação do sujeito para fomentar o olhar do indivíduo para esta nova sociedade, de maneira a enxergar o Bem-Viver como forma de termos um mundo melhor em todos os sentidos.

Trazer a relação entre Pedagogia Freinet e Bem-Viver neste momento atual é refletir como inserir uma base democrática de construção do conhecimento, diferente da 
forma de ensino tradicional ${ }^{7}$. Freinet traz em sua pedagogia quatro princípios ou eixos norteadores que podemos relacionar ao Bem-Viver no processo de ensino e aprendizagem na escola. São eles: a cooperação, comunicação ou socialização, afetividade e documentação sendo desenvolvidos a partir das técnicas que o educador criou.

Pedagogia Freinet surgiu para atender a necessidade vital da criança: chegar ao seu pleno desabrochar como um indivíduo autônomo, um ser social, responsável, co-detentor e co-edificador de uma cultura.

Como?

Desenvolvendo:

O Senso de responsabilidade.

O Senso Cooperativo.

A Sociabilidade.

O Julgamento Pessoal.

A Reflexão Individual e Coletiva.

A Criatividade.

A Expressão.

A Comunicação.

O "Saber Fazer" (Know-How).

Os Conhecimentos Úteis.

A capacidade de reduzir os pontos de desigualdades sócio-culturais.

Na Pedagogia Freinet, a escola deve assegurar uma verdadeira formação, aquela que dá o mesmo valor à inteligência verbo-conceitual e aos mais simples trabalhos feitos com as mãos.

Esse é o espírito com que a escola deve tentar alcançar objetivos (SAMPAIO, 1989, p. 213).

Na reflexão que Sampaio (1989) faz sobre a Pedagogia Freinet, podemos exemplificar suas técnicas, práticas e princípios no ensino e aprendizagem no ambiente escolar, utilizando os princípios norteadores da sua pedagogia. Traz a cooperação na formação dos alunos e alunas, os cidadãos que cooperam uns com os outros, sendo solidários, capazes de saber trabalhar coletivamente, de construir o conhecimento todos juntos, tornando-lhes pessoas mais humanas. Outro princípio é a comunicação ou socialização, desde cedo as crianças aprendem a falar o que pensam, o que sentem, o que aconteceu, o que acreditam e ter argumentação, trazendo a voz delas como fundamental em sala para todos(as), alunos(as) e professores(as), deixando registrado seja através de um álbum com as histórias das novidades, seja através do que ocorreu na escola no livro da vida ${ }^{8}$. Conseguem, se comunicando e socializando, tornar-se cidadãos que tenham voz, empoderados(as) para falarem aquilo que querem, compreendendo que também deve existir a todo momento o respeito.

Os registros nos princípios de Freinet são colocados como documentação que diariamente acontece através dos diários de classe, dos livros da vida, das atividades desenvolvidas em sala de aula e outros registros realizados pelos(as) alunos(as) e professores(as). O último princípio, a afetividade, diz respeito às emoções, a doar-se ao outro, dar amor e estar aberto para receber, criar laços de amizades e irmandades, sendo

\footnotetext{
${ }^{7}$ De acordo com Freinet, o ensino tradicional impõe os passos a serem seguidos, dá o modelo e julga o resultado. Seu objetivo é a conformidade a uma norma definida por ele. Considera então normal excluir e culpar todos aqueles que não estão conformes (ICEM, 1979).

${ }^{8}$ Livro da vida é um grande caderno com folhas brancas em que diariamente as crianças relatam o que ocorreu durante o dia (atividades, brincadeiras, quem faltou naquele dia, novidades de algo que aconteceu na escola ou fora dela, se houveram crianças que se machucaram, brigas e outros). Quando as crianças não sabem escrever a professora escreve e eles (as) enfeitam, caso já saibam, fazem tudo sozinhas (os) no final da aula.
} 
carinhosos e se preocupando com o outro, deixando claro que todos temos sentimentos e que relações de amor são importantes.

Freinet também traz em sua pedagogia a relação com o meio em que se vive, trazendo para sala de aula vivências de algo que ocorreu fora dela, ou levando os alunos para a Aula-Passeio, na qual se passeia com os alunos pelas redondezas da escola para observar o que ocorre, o som dos pássaros, as estações do ano, as indústrias, ruas, trânsito, geografia, entre outros acontecimentos. Depois, leva-se o assunto para sala, pede-se que todos que participaram falem um pouco sobre o que viram, ouviram, sentiram, e a partir daí constrói-se o conhecimento com eles em pesquisa seja sobre os animais, ou sobre as estações, ou então escreve-se com eles sobre o passeio através do texto coletivo, ou pede-se um desenho livre sobre o que vivenciaram. Esta técnica é um exemplo de como as formas de ensinar e aprender podem trazer o Bem-Viver na educação escolar.

Através do método freneitiano podemos fomentar uma transformação social, uma sociedade mais justa, igualitária, como diz Sampaio ao citar uma das invariantes de Freinet: "A democracia de amanhã prepara-se pela democracia na escola" (SAMPAIO, 1989). Mas que cidadãos queremos "criar" para nossa sociedade?

Segundo Brandão (2005):

\begin{abstract}
A insistência com que os verbos "fazer", "ter" e "conquistar" em lugar do "ser", "criar" e "realizar", precedem palavras que sugerem os mais desejados sonhos da vida de todos nós, bem indica a maneira a ação instrumental tornada real na posse de coisas e na conquista posições sociais, é cada vez mais o espelho daquilo que se vê refletida na pessoa socialmente feliz, isso é: "rica" "famosa" ou de "sucesso" (BRANDÃO, 2005, p. 35).
\end{abstract}

$\mathrm{Na}$ sociedade em que vivemos, Brandão (2005) escreve sobre os desejos da população que enxerga no capitalismo em que se vive a conquista do "Ter" maior do que a do "Ser", e essa visão de mundo, na qual quem tem mais é melhor, deve ser desconstruída e o espaço para isso é a escola. É nela que através da educação se pode ter esperança na construção de conhecimento crítico desde pequenos(as). Trazendo uma transformação de pensamento desses cidadãos podemos acreditar numa nova sociedade, com seres humanos menos oprimidos, mais humanizados, solidários, críticos, cooperativos, afetuosos, preocupados com a sociedade e o mundo em que vivem de forma geral. São esses alunos e alunas que formamos hoje, que no futuro serão pessoas mais conscientes de um mundo pelo e para o Bem-Viver, como Freinet (1969) coloca:

A Escola que não prepara para a vida, já não serve a vida; e essa sua definitiva e radical condenação. Cada vez mais, a verdadeira formação das crianças, a sua adaptação ao mundo actual e às possibilidades de amanhã, se efectuam mais ou menos metodicamente fora da escola, porque a escola não possui aptidões para tal (FREINET, 1969, p. 19).

A Pedagogia Freinet, portanto, traz a possibilidade do diálogo com a filosofia do Bem-Viver na medida em que defende uma educação pela e para a vida, incentivando a formação de sujeitos que tenham um novo olhar e uma nova percepção de mundo, que visem o Bem-Viver como defendido na cosmovisão indígena. 


\title{
INTERFACE DO BEM-VIVER COM A ARTE/EDUCAÇÃ ${ }^{9}$
}

A proposta do Bem-Viver anuncia uma reconfiguração da vida humana em sociedade. O Bem-Viver, nesse sentido, propõe uma mudança de percepção, uma ampliação de nossa visão humana tanto para nossos mundos internos quanto para os mundos externos.

Quijano (2013), diz que desde o advento da modernidade vivemos um processo de tecnocratização/instrumentalização/mercantização da subjetividade e da experiência de vida dos indivíduos, que a indústria cultural e a racionalidade instrumental/moderna impregnam nosso imaginário e conformam nossos processos de subjetivação, levandonos à reprodução e repetição de um modo de vida hegemônico e eurocentrado, enraizado na colonialidade e em todo o apagamento da diversidade cultural.

A resistência à lógica instrumental eurocêntrica, as estratégias para estabelecer e cristalizar a utopia de uma reconfiguração da sociedade em seu conjunto, são colocadas nos seguintes termos por Acosta (2016):

\begin{abstract}
Há que escrever todos os rascunhos possíveis de uma utopia que ainda será construída. Uma utopia que implica a crítica da realidade sobre princípios forjados no Bem-Viver. Uma utopia que, por ser um projeto de vida solidário e sustentável, deve ser uma alternativa imaginada coletivamente, conquistada e construída politicamente, e executada democraticamente a todo momento e circunstância. Citando o jornalista alemão Thomas Pampuch, o objetivo é superar a miséria da modernização - o que não significa modernizar a miséria (ACOSTA, 2016, p. 198).
\end{abstract}

As capacidades de crítica da realidade e de superação da miséria da modernização, passam necessariamente pela urgência de revisão dos processos educativos, pois a educação em nossa sociedade sempre esteve e ainda está a serviço da colonialidade e da manutenção do status quo. A educação pela via da arte se manifesta então como possibilidade de reconexão dos sujeitos com sua sensibilidade, com sua potência criativa, como ação contrária ao "[...] empobrecimento da experiência" e aos frutos amargos do progresso enunciados por Benjamin (1987) em seu texto Experiência e Pobreza, no qual diz: "[...] qual o valor de todo o nosso patrimônio cultural, se a experiência não mais o vincula a nós?" (BENJAMIN, 1987, p. 115), fazendo uma crítica ao quanto a técnica afastou os humanos da experiência e transformou a arte e a cultura em objetos de consumo.

No contexto brasileiro, a educadora Barbosa defende a Arte/Educação como via de regra para o desenvolvimento de uma consciência e identificação cultural, para colocar em suspensão a hegemonia e o apagamento cultural instaurados. No entanto, não deixa de ter um olhar crítico para a maneira como a arte é trabalhada nas escolas, para a forma como o ensino da arte se desenvolveu e se desenvolve no Brasil. Em ArteEducação no Brasil, Barbosa (2012) apresenta um panorama histórico sobre a forma como arte e educação se relacionaram no Brasil desde a chegada da Missão Francesa até o Modernismo, de forma a expor as origens de preconceitos contra o ensino da Arte, assim como o desprezo pelas funções da arte na evolução do pensamento pedagógico, e o desinteresse de artistas em refletir sobre seus métodos de ensino.

\footnotetext{
${ }^{9}$ Em Arte/Educação Contemporânea: Consonâncias Internacionais, Barbosa (2005) usa as expressões ensino da Arte e Arte/Educação como equivalentes e diz que prefere a designação Arte/Educação (com barra) por recomendação de um linguista à Lúcia Pimentel por utilizarem o hífen para designar ArteEducação com o sentido de pertencimento, a barra de acordo com a autora significa "pertencer a" (BARBOSA, 2005, p. 21).
} 
Em Arte-Educação: leitura no subsolo, Barbosa (2015) organizou uma coletânea de textos de pesquisadores renomados nos estudos de Arte/Educação, e em entrevista com Ernest Gombrich ${ }^{10}$ perguntou a ele: “Arte se ensina?", e a resposta dele foi: "Não, mas isto não é propriamente arte-educação. Eu nunca estive numa sala de aula, nunca ensinei arte" (BARBOSA, 2015, p. 63). Do que se trata então, afinal, a Arte/Educação? Barbosa (2015) aponta Arte/Educação como ensino por meio da arte, uma interpenetração entre a arte e a educação, servindo a arte como ferramenta de aprendizagem de todas as disciplinas, não uma disciplina complementar nas escolas.

A Arte/Educação ocasiona deslocamentos na realidade instituída à medida que se apresenta como dispositivo emancipador, tendo em vista mobilizar os sujeitos implicados no contexto educativo a intervir no mundo, seja por meio do ato criativo individual, seja pela apreciação do gesto artístico de outrem, desenvolvido no presente ou no passado. A Arte/Educação que se pretende política é pulsão de vida e implica alteridade. Rancière (2002) fala sobre a igualdade de inteligências em $O$ mestre ignorante e iguala o simples artesão a seu mestre, equiparando o fazer ao saber, criticando a sobreposição de uma inteligência à outra e o processo de embrutecimento que decorre disso. Em outra obra sua, $O$ espectador emancipado (2014), o autor discute que no teatro renovado ${ }^{11}$ o público é conclamado a ser ator, a ter papel ativo no espetáculo, ou seja, a se emancipar.

Ao falarmos de Arte/Educação no sentido político, remetemo-nos não apenas ao conteúdo político que um objeto artístico pode assumir, mas também aos lugares por onde a arte circula, a uma intervenção consciente da arte nas estruturas de poder, à subversão da arte como produto e a uma valorização da arte como materialização de experiências humanas com o desconhecido e com o conhecido. Sendo assim, Camnitzer (2018), curador, artista e acadêmico diz em seu texto intitulado $O$ ensino da arte como fraude:

Se a arte fosse realmente uma atitude e uma maneira de se aproximar do
conhecimento, não importaria em que meio ocorrem as ideias, as revelações.
A única coisa que importa é que elas possuem um lugar e são comunicadas
corretamente. Quando discuto arte, acredito em seres politizados, não em
programas políticos. De modo que não acredito que se trate de fazer arte
política, mas de politizar as pessoas e ajudá-las a fazer arte. No final da
década de 1960, Paulo Freire resumiu isso ao escrever que antes de ler a
palavra é preciso ler o mundo (CAMNITZER, 2018, p. 129).

As oficinas e laboratórios de artes desenvolvidos em contextos educativos, se apresentam como possibilidade de suspensão dos paradigmas político-sociais que envolvem o universo da educação e também das artes, como coloca Camnitzer (2018), desde que as práticas educativas nestes espaços não se limitem a uma mera "transmissão de informação interdisciplinar".

A Arte/Educação pode ser aliada à proposta do Bem-Viver no que diz respeito à luta pelo desengessamento das subjetividades, das formas de ser, de saber e do fazer humanos, no que tange a uma subversão da lógica da instrumentalização em nome da experiência. O Bem-Viver não vai se materializar em nossa sociedade num passe de mágica, em que a realidade é mudada instantaneamente por um mágico em um

\footnotetext{
${ }^{10}$ Ernest Gombrich foi um célebre historiador da arte, diretor do Warburg Institute e professor na Universidade de Londres, em Oxford, Cambridge, Princeton e Harvard.

${ }^{11} \mathrm{O}$ teatro reformado discutido por Rancière (2014) é desenvolvido principalmente por Brecht e Artaud, a partir de perspectivas distintas, e tem como premissa deslocar o papel do espectador passivo para um papel ativo e participativo diante do espetáculo.
} 
espetáculo. A magia, todavia, está no cerne da própria concepção de Bem-Viver na cosmovisão indígena, como uma experiência de percepção de um mundo sensível, que se traduz em arte. A educação por meio da arte está embebida de resistência, assim como a proposta de Bem-Viver advinda da permanência dos povos indígenas na sociedade, e resistência se faz persistindo concretamente, dia após dia, na História.

\section{INTERFACE DO BEM-VIVER COM A EDUCAÇÃO DAS RELAÇÕES ÉTNICO-RACIAIS}

Vivemos em uma sociedade formada por diferentes grupos étnico-raciais, território onde convivem cerca de 200 povos indígenas, mais de 2.200 comunidades remanescentes de quilombolas, além das populações portuguesas, italianas, japonesas, africanas e outras que aqui vivem (SILVÉRIO; MATTIOLI; MADEIRA, 2012).

A maioria das pessoas da nossa população se declaram negras ou pardas, 56,20\% de acordo com um estudo realizado pela Pesquisa Nacional por Amostra de Domicílios Contínua - (PNAD Contínua) (IBGE, 2019). Esses dados não fazem com que as relações étnico-raciais estabelecidas socialmente sejam equânimes e democráticas. Existem racismos, discriminações e preconceitos contra as pessoas negras e indígenas que as colocam em situação de desigualdade social, econômica, que as marginalizam e as colocam em situações de inferioridade e vulnerabilidade.

Muitas foram as lutas do Movimento Negro e de estudiosos para transformar a realidade de preconceitos e discriminações no ambiente escolar e em nossa sociedade. Em 2003 e 2008, as leis 10.639 (BRASIL, 2003) e 11.645 (BRASIL, 2008) alteraram a Lei de Diretrizes e Bases da Educação Nacional (LDB) e estabeleceram a obrigatoriedade do ensino sobre "História e cultura Africana e Afro-brasileira e indígenas" na educação básica de todas as escolas públicas e privadas do país.

Em 2004, foram aprovadas as Diretrizes Curriculares Nacionais para a Educação das Relações Étnico-Raciais e para o Ensino de História e Cultura Afro-Brasileira e Africana (BRASIL, 2004), reconhecendo a necessidade de se articular o presente, o passado e o futuro, para o reconhecimento e valorização dos negros, africanos e indígenas na construção econômica, social e cultural de nossa sociedade, além de uma educação voltada para as relações étnico-raciais.

As escolas, assim como as demais instituições e espaços, estão inseridas numa estrutura social discriminatória e hierárquica e não estão imunes a práticas racistas e preconceituosas. Os efeitos destas práticas trazem prejuízos, dor e sofrimentos para todos os envolvidos, como nos atentam as Diretrizes Curriculares para a Educação das Relações Étnico-Raciais (BRASIL, 2004).

Segundo as Diretrizes (BRASIL, 2004), a Educação das Relações Étnico-Raciais já ocorre nas escolas, mas de uma forma conflituosa e estereotipada, na qual as pessoas negras, seus costumes e valores são inferiorizados. O documento menciona que educar para as relações étnico-raciais é questionar e rever as relações étnico-raciais já existentes, entre negros e não negros, adultos e crianças, baseadas em preconceitos, estereótipos depreciativos, atitudes e palavras que expressam sentimentos de superioridade, inferioridade.

Ainda com o documento, sabemos que a Educação das Relações Étnico-Raciais requer aprendizagens "[...] entre brancos e negros, troca de conhecimentos, quebra de desconfianças, projeto conjunto para construção de uma sociedade justa, igual e equânime" (BRASIL, 2004, p. 14). O referido texto explicita que para isto ocorrer "[...] é necessário que as instituições de ensino se constituam em espaços democráticos de 
produção e divulgação de conhecimentos e de posturas que visam a uma sociedade justa" (BRASIL, 2004, p. 14).

Com Freire (1987), percebemos a educação como todos os processos educativos que nós, seres humanos, elaboramos em todos os espaços que frequentamos e nas relações que estabelecemos - pode ser tanto bancária, legitimadora da opressão, usada para reforçar as desigualdades entre os homens e as mulheres, como também pode ser emancipadora-libertadora, transformando sujeitos e mundos em algo melhor, mais humanizados.

Freire (1987) discorre que na concepção da educação bancária, não existe diálogo, o educador deposita seus conhecimentos nos educandos, cabendo a estes apenas receber, memorizar e repetir sem entender o significado do que está sendo transmitido, o ensino educa para a passividade, ingenuidade, para a acriticidade, não existe transformação, não existe saber, humanitarismo, nem criatividade. As pessoas não podem tornar-se autônomas e nem sujeitos de suas próprias vidas, pois falta-lhes consciência crítica de se libertarem da situação de opressão.

Freire (1987) nos propõe uma educação libertadora pela qual os indivíduos se tornem sujeitos do ato de se educar. Tornem-se conscientes de si mesmos inseridos no mundo em que vivem. Nesta concepção, a libertação é uma práxis que implica na ação e reflexão do indivíduo sobre o mundo em que ele vive para transformá-lo. É a passagem de uma consciência acrítica e ingênua para uma consciência crítica que visa a autonomia, o diálogo e a humanização.

No mesmo sentido da educação libertadora e emancipadora, proposta por Freire (1987), a Educação das Relações Étnico-Raciais propõe a superação de qualquer educação que se pretenda ser dominadora, acrítica e opressora.

Souza (2012, p. 107) discorre que "[...] só é possível educar nas relações que estamos vivenciando, para assim nos prepararmos para as demais relações que iremos vivenciar".

Com esses dizeres, podemos compreender que educar nas e para as Relações Étnico-Raciais é um processo de formação humana, algo que deve ser desenvolvido constantemente, com relações que valorizem o respeito, o diálogo, as relações horizontais entre todos/as independente de idade, raça, crenças e classes sociais, podendo assim possibilitar uma maior humanização e práticas mais equânimes e democráticas.

O Bem-Viver é considerado neste estudo como uma filosofia de vida, como possibilitadora de transformações sociais, nos atenta à necessidade de mudarmos nosso modelo de existência: em que o individualismo, o consumismo, a competição e as relações hierárquicas prevalecem. Tanto na Filosofia do Bem-Viver, quanto na Educação das Relações Étnico-Raciais vemos a valorização de nossa ancestralidade, do conviver, da comunidade, do respeito à diversidade, ambas nos propõe o romper com práticas coloniais, hegemônicas, discriminatórias, individuais para que pensemos no bem da coletividade.

De que lugar se projetam os paraquedas? Do lugar onde são possíveis as visões e o sonho. Um outro lugar que a gente pode habitar além dessa terra dura: o lugar do sonho. [...] O sonho como experiência de pessoas iniciadas numa tradição para sonhar. Assim como quem vai para uma escola aprender uma prática, um conteúdo, uma meditação, uma dança, pode ser iniciado nessa instituição para seguir, avançar num lugar do sonho. Alguns xamãs ou mágicos habitam esses lugares ou têm passagem por eles. São lugares com conexão com o mundo que partilhamos; não é um mundo paralelo, mas que tem uma potência diferente (KRENAK, 2019, p. 32). 
Nesse sentido, fazendo uma analogia com a fala de Krenak (2019) os paraquedas representam a esperança de mudanças e transformações que a filosofia do Bem-Viver e a educação nos possibilitam praticar.

\section{CONSIDERAÇÕES FINAIS}

Acreditamos que a mudança pode acontecer e devemos buscar, para além da humanização, sonhar e fazer este sonho acontecer. A sorte de estarmos vivos, poder conviver nesse mundo, em harmonia com a natureza, é algo incrível, pois não há tempo demarcado que limite o seu uso, apenas a ambição humana. Tanto na prática escolar, quanto na educação por meio da arte e na educação das relações étnico-raciais, precisamos sonhar que é possível viabilizar o Bem-Viver, por isso trouxemos neste ensaio reflexões sobre a Pedagogia Freinet, a Arte/Educação e a Educação nas Relações Étnico-Raciais como caminhos para desenvolver esta filosofia, com práticas educativas alinhadas com a vida.

Através dos princípios orientadores da Pedagogia de Freinet e suas técnicas, trouxemos fundamentos de sua teoria e prática que se aproximam dos princípios do Bem-Viver, assim como na Arte/Educação, a expressão artística ligada a uma reconexão dos sujeitos consigo mesmos, com o outro e com o mundo, com a perspectiva dialógica e com a sensibilidade, se alinhando com a mesma filosofia. Já a Educação das Relações Étnico-Raciais é transversal às propostas anteriores, podendo refletir sobre questões éticas, o respeito a diferenças, valorização da pluralidade e multiculturalismo, corroborando a ecologia dos saberes preconizada por Santos (2007).

Guajajara (2020), principal liderança feminina indígena no Brasil, afirmou que o que estamos vivendo "Não é uma luta de índio, mas pelo planeta". Os dizeres da indígena Guajajara, e os dizeres dos autores que trouxemos para este diálogo nos fazem refletir sobre a real necessidade de mudanças ética, social, de postura, pensando em nossa existência e sobrevivência. Percebe-se que há um eco entre os pensadores indígenas. Esse eco é a plena consciência de que o ser humano não pode controlar tudo como ambiciona, há algo que nos escapa, e reconhecer isso, nos conectarmos uns com outros a favor da vida, é o que nos faz fortes. Essa é a premissa que ecoa entre todos os pensadores indígenas, não importa a que etnia pertençam. Unidos, eles resistem há séculos de opressão em um sistema econômico-social assassino.

A humanidade, portanto, de acordo com a filosofia indígena não está cumprindo com seus próprios direitos humanos, pois não disfruta com seu direito mais essencial, o direito à vida, tendo em vista que está destruindo as outras formas de vida do planeta e o próprio planeta em que vive.

As reflexões apresentadas neste ensaio apontam o diálogo entre diferentes autores e culturas com a filosofia do Bem-Viver, que defendem uma luta de todos os humanos pela vida e pela liberdade, que se desenvolve com diferentes roupagens em diversas áreas de atuação e de estudos, que é dita com vários termos e conceitos e colocada em prática das mais diferentes maneiras, mas que no fim dizem respeito a algo comum, ao sonho.

\section{REFERÊNCIAS}

ACOSTA, A. O bem-viver: uma oportunidade para imaginar outros mundos. São Paulo: Elefante Editora, 2016. 
Alessandra Guerra da Silva Oliveira; Carolina Laureto Hora; Gabriela Luchesi Martins

BARBOSA, A. M. Entrevista com Ernest Gombrich. In: BARBOSA, A. M. (org.). Arte-educação: leitura no subsolo. São Paulo: Cortez, 2015. p. 50-68.

BARbOSA, A. M. Arte-educação no Brasil. São Paulo: Perspectiva, 2012.

BARBOSA, A. M. (org.). Arte/educação contemporânea: consonâncias internacionais. São Paulo: Cortez, 2005.

BENJAMIN, W. Experiência e pobreza. In: BENJAMIN, W. Magia e técnica, arte e política. São Paulo: Brasiliense, 1987. p. 114-119.

BRANDÃO, C. R. A canção das sete cores: educando para a paz. São Paulo: Editora Contexto, 2005.

BRASIL. Lei 11.645, de 10 de março de 2008: altera a Lei $n^{\circ}$ 9.394, de 20 de dezembro de 1996, modificada pela Lei no 10.639, de 9 de janeiro de 2003, que estabelece as diretrizes e bases da educação nacional, para incluir no currículo oficial da rede de ensino a obrigatoriedade da temática "História e Cultura Afro-Brasileira e Indígena". Brasília: Casa Civil 2008.

BRASIL. Ministério da Educação. Diretrizes Curriculares Nacionais para a Educação das Relações Étnico-Raciais e para o Ensino de História e Cultura Afro-Brasileira e Africana. Brasília: MEC, 2004. Disponível em: http://portal.mec.gov.br/dmdocuments/cnecp_003.pdf. Acesso em: 15 jul. 2020.

BRASIL. Lei 10.639, de 9 de janeiro de 2003: altera a Lei no 9.394, de 20 de dezembro de 1996, que estabelece as diretrizes e bases da educação nacional, para incluir no currículo oficial da Rede de Ensino a obrigatoriedade da temática "História e Cultura Afro-Brasileira", e dá outras providências. Brasília: Casa Civil, 2003. Disponível em: http://www.planalto.gov.br/ccivil_03/Leis/2003/L10.639.htm. Acesso em: 20 ago. 2020.

CAMNITZER, L. O ensino da arte como fraude. In: CERVETTO, R.; LÓPEZ, M. (org.). Agite antes de usar: deslocamentos educativos, sociais e artísticos na América Latina. São Paulo: Edições Sesc, 2018. p. 125-137.

CASTRO. E. Prefácio - O recado da mata. In: KOPENAWA, D.; ALBERT, B. A queda do céu : palavras de um xamã yanomami. São Paulo: Companhia das Letras, 2015. p. 11-41.

CORTELLA, M. S. Educação, convivência e ética: audácia e esperança. São Paulo: Cortez, 2015.

FREINET. C. Para uma escola do povo: guia prático para organização material, técnica e pedagógica da escola popular. Lisboa: Editorial Presença, 1969.

FREIRE, P. Pedagogia da esperança: um reencontro com a pedagogia do oprimido. Rio de Janeiro: Paz e Terra, 1992.

FREIRE, P. Pedagogia do oprimido. 17. ed. Rio de Janeiro: Paz e Terra, 1987.

GUAJAJARA, S. Sonia Guajajara: "Não é uma luta de índio, mas pelo planeta". Catraca Livre, 05 jun. 2020. Disponível em: https://catracalivre.com.br/cidadania/sonia-guajajara-nao-e-uma-luta-de-indio-maspelo-planeta/. Acesso em: 25 ago. 2020.

IBGE. PNAD Contínua: Pesquisa Nacional por Amostra de Domicílios Contínua. 2019. Disponível em: https://biblioteca.ibge.gov.br/visualizacao/livros/liv101707_informativo.pdf. Acesso em: 15 jun. 2020.

ICEM. Instituto Cooperativo da Escola Moderna. Primeiros contatos com a Pedagogia Freinet. Dossiê Pedagógico da Revista L’Educateur. Tradução: Ruth Joffily Dias, 1979.

KOPENAWA, D.; ALBERT, B. A queda do céu : palavras de um xamã yanomami. São Paulo: Companhia das Letras, 2015.

KRENAK, A. O amanhã não está à venda. São Paulo: Companhia das Letras, 2020. 
KRENAK, A. Ideias para adiar o fim do mundo. São Paulo: Companhia das Letras, 2019.

KRENAK, A.; RIBEIRO, S. Mesa 6: Sonhos para adiar o fim do mundo, com Ailton Krenak e Sidarta Ribeiro. Mediação: Carolina Pires. Youtube: 24 mai. 2020. Disponível em: https://www.youtube.com/watch?v=95tOtpk4Bnw. Acesso em: 04 out. 2020.

QUIJANO, A. Bem-viver: entre o "desenvolvimento" e a "des/colonialidade" do poder. Revista da Faculdade de Direito da UFG, v. 37, n. 1, p. 46-57, jan./jun. 2013.

RANCIÈRE, J. O espectador emancipado. Tadrução: Ivone C. Benedetti. São Paulo: Martins Fontes, 2014.

RANCIÈRE, J. O mestre ignorante: cinco lições sobre emancipação intelectual. Tradução: Lilian do Valle. Belo Horizonte: Autêntica, 2002.

SAMPAIO, R. M. W. F. Freinet: evolução histórica e atualidades. São Paulo: Editora Scipione Ltda., 1989.

SANTOS, B. S. A cruel pedagogia do vírus. Coimbra: Almedina, 2020.

SANTOS, B. S. Para além do pensamento abissal: Das linhas globais a uma ecologia de saberes. Revista Crítica de Ciências Sociais, n. 78, p. 3-46, out. 2007.

SILVÉRIO, V. R.; MATTIOLI; É. A. K.; MADEIRA, T. F. L. Relações étnico-raciais: um percurso para educadores São Carlos: EdUFSCar, 2012.

SOUZA, E. L. Percepções de infância de crianças negras por professoras de educação infantil. 2012. 123 f. Dissertação (Mestrado em Educação) - Centro de Educação e Ciências Humanas, Universidade Federal de São Carlos, São Carlos, 2012.

TURINO. C. Prefácio à edição brasileira. In: ACOSTA, A. O bem-viver: uma oportunidade para imaginar outros mundos. São Paulo: Elefante Editora, 2016. p. 13-17.

Recebido em: 30 nov. 2020. Aprovado em: 22 abr. 2021. 